\title{
Population-based survey of overweight and obesity and the associated factors in peri-urban and rural Eastern Uganda
}

\author{
Barbara Eva Kirunda ${ }^{1,2^{*}}$, Lars Thore Fadnes ${ }^{2,3}$, Henry Wamani ${ }^{4}$, Jan Van den Broeck ${ }^{2 \wedge}$ and Thorkild Tylleskär ${ }^{2}$
}

\begin{abstract}
Background: In sub-Saharan Africa (SSA), the rising prevalence of overweight, obesity and non-communicable diseases co-exists with the high burden of under-nutrition. The paucity of data on adulthood overweight and obesity, disaggregated by socio-demographic characteristics and in rural settings in SSA calls for research. We determined the prevalence of underweight, overweight/obesity and associated factors among adults in peri-urban and rural Uganda.
\end{abstract}

Methods: A cross-sectional study of 1210 randomly selected adults aged $\geq 18$ years was conducted in Iganga-Mayuge Health and Demographic Surveillance Site in eastern Uganda in 2013. Height, weight and socio-demographic variables were assessed. Overweight was defined as BMl $=25.0-29.99 \mathrm{~kg} / \mathrm{m}^{2}$, obesity $\geq 30 \mathrm{~kg} / \mathrm{m}^{2}$ and overweight/ obesity $\geq 25 \mathrm{~kg} / \mathrm{m}^{2}$. Logistic regression was used to identify factors associated with overweight/obesity.

Results: Of the participants, $7 \%$ were underweight ( $8.1 \%$ of men; $5.9 \%$ of women, $p=0.99$ ); $17.8 \%$ were overweight (12.4\% of men; $23.1 \%$ of women, $p<0.001$ ); and $7 \%$ were obese ( $2.0 \%$ of men; $12.7 \%$ of women, $p<0.001)$. Overweight prevalence was $15.8 \%$ and $23.8 \%$ among rural and peri-urban adults, respectively $(p<0.001)$. Obesity prevalence was $3.9 \%$ and $17.8 \%$ among rural and peri-urban adults, respectively $(p<0.001)$. Factors associated with overweight/obesity were: being female, adjusted odds ratio (AOR) 4.3 (95\% confidence interval (PloS one 8:e75640, 20013) 3.2-5.9); peri-urban residence AOR 2.6 (1.9-3.6); being in age group 35-44, AOR 3.1 (1.8-5.3); 45-54 AOR 4.1 (2.3-7.3); 55-64 AOR 2.6 (1.4-5.0); $\geq 65$ years AOR 3.1 (1.6-6.0); and having socio-economic status (SES) in the third AOR 2.8 (1.7-4.6), fourth $2.5(1.5-4.2)$ and fifth 2.7 (1.6-4.4) quintile.

Conclusions: Overweight/obesity was prevalent among adults. Overweight/obese was associated with being female, being aged 35 years and older, residing in a peri-urban area and having a higher SES. The time has come to develop interventions to prevent and control overweight/obesity.

Keywords: Overweight, Obesity, Associated factors, Peri-urban and rural Uganda

\section{Background}

Worldwide, the prevalence of overweight and obesity are on the rise $[1,2]$ while the prevalence of under-nutrition has not significantly changed over the last decade [3]. While underweight prevalence is still high [4], overweight and obesity are now prevalent in low- and

\footnotetext{
* Correspondence: bkirunda@musph.ac.ug

Deceased

'Department of Epidemiology and Biostatistics, Makerere University College of Health Sciences, School of Public Health, P.O. Box 7072, Kampala, Uganda ${ }^{2}$ Centre for International Health, University of Bergen, P.O. Box 7800, 5020 Bergen, Norway

Full list of author information is available at the end of the article
}

middle-income countries $[4,5]$, including those in Africa $[1,6]$, at a prevalence of $20-50 \%$ [7-12] in urban areas and $7-30 \%$ in rural areas [9-15].

In SSA, the rising prevalence of overweight and obesity co-exists with the under-nutrition epidemic $[16,17]$ and the increasing prevalence of non-communicable diseases (NCD) with an anticipated largest increase in NCD deaths of $27 \%$ in Africa over the next decade [18]. Underweight, overweight and obesity are known risk factors for NCDs [19, 20]. Similarly, the Uganda Demographic and Health Surveys (UDHS) from 1995 to 2011 reported an increasing prevalence of overweight and 
obesity from 8 to $18.8 \%$ while underweight prevalence stagnated at $10-12 \%[21,22]$.

However, evidence examining the influence of the individual, social and built environment on overweight/obesity is still patchy $[23,24]$ and limited to urban and suburban populations [24] in high-income countries which cannot be generalized to low- and middle-income countries [25] and this is even more true in rural settings.

The paucity of research on obesity and physical inactivity disaggregated by age, sex and residence [26] and the influence of the environment on overweight/ obesity in Africa [25] calls for research in SSA [27] among peri-urban and rural populations in order to develop effective, culturally sensitive, context-specific and population-based interventions for the prevention of obesity and NCDs [25]. The objective of this study was to determine the prevalence of underweight, overweight and obesity and associated factors in a populationbased sample of adults in peri-urban and rural Uganda.

\section{Methods}

\section{Study design and setting}

An observational cross-sectional study was conducted in 2013 among adults drawn from an active study cohort of 1 January 2005 to 30 September 2013 in the IgangaMayuge Health and Demographic Surveillance Site (IMHDSS) located in Iganga and Mayuge Districts in eastern Uganda, $120 \mathrm{~km}$ east of Kampala, the capital. The IMHDSS had an estimated population size of 80,000 people in 2013 of whom $51.2 \%$ are females. The estimated number of households is 13,000 across an area of about $155 \mathrm{~km}^{2}$. The IMHDSS is composed of 65 villages with about $38 \%$ of the population residing in peri-urban villages. Routine data collection is regularly carried out for births, deaths and their causes, marriages, in- and out-migration, education and socio-economic status. In addition to these routine surveillance activities, data are also collected for special studies.

\section{Study population and sampling}

The study population comprised of men and nonpregnant women aged 18 years and above residing in the IMHDSS for at least 4 months, who had an individual identification IMHDSS number and were part of a household with an IMHDSS identification number. Adults who were ill, for whom physical activity was constrained or who were unable to communicate with the research team were excluded from participating in the study. Cluster sampling [28] was used to select participants from the active HDSS study cohort, with villages being the clusters. Probability proportionate to size sampling was used to select 40 villages, from which 30 households/participants were selected by simple random sampling using Stata data analysis and statistical software. From each village, an equal number of female and male respondents were randomly selected. In this study, a household was defined as a group of people who had been living and eating their meals together for at least 6 of the 12 months preceding the study. Study participants who were not found at their place of residence were replaced by individuals in neighbouring households who were matched by sex using the IMHDSS village lists.

\section{Data collection strategy}

A field team of ten research assistants and one supervisor underwent a three-day standardized training on the study objectives, administration of the questionnaire and physical measurements of body weight and height. A semi-structured questionnaire was used to collect quantitative data on physical measurements of body weight and height and socio-demographic variables including sex, age, residence, marital status, religion, education level, occupation in the previous month, average monthly earnings and ownership of assets for purposes of assessing socio-economic status. Validated questions on socio-demographic variables were adopted from the IMHDSS [29] surveillance data collection tools and the Uganda Demographic and Health Survey [22]. The questionnaire was translated into the local language and pretested in the neighbouring district to check on the ease of comprehension of questions and anomalies were corrected. The field assistants worked in pairs composed of a nutrition assessor and an interviewer so as to optimize the quality of anthropometric measurements. The questionnaires from the field were checked daily for errors and missing data by the quality assurance officer.

\section{Outcome measure}

For each study participant, anthropometric measurements of body height and weight were assessed using standard protocols, with subjects standing upright, not wearing shoes and wearing light weight clothes. Body height in centimetres $(\mathrm{cm})$ was measured twice to the nearest $0.1 \mathrm{~cm}$ using $\mathrm{Seca}^{\mathrm{Tm}} 213$ portable stadiometers (Seca GmbH \& Co. Kg., Hamburg, Germany). Body weight in kilograms $(\mathrm{kg})$ was measured twice to the nearest $0.1 \mathrm{~kg}$ using calibrated Seca ${ }^{\text {Tx }} 876$ digital weighing scale (Seca GmbH \& Co. Kg., Hamburg, Germany). Final height and weight values were obtained as averages of the two measurements. The intraclass correlation coefficients (ICCs) for height and weight measurements within participants were 0.982 and 0.960 respectively, suggesting that intra-rater reliability was well above acceptable levels [30]. The outcome variable, body mass index was calculated and used as indicator of underweight (BMI $\left.<18.5 \mathrm{~kg} / \mathrm{m}^{2}\right)$, normal weight $(\mathrm{BMI}=18.5-$ $\left.24.99 \mathrm{~kg} / \mathrm{m}^{2}\right)$, overweight $\left(\mathrm{BMI}=25.0-29.99 \mathrm{~kg} / \mathrm{m}^{2}\right)$ 
and obesity (BMI $\geq 30 \mathrm{~kg} / \mathrm{m}^{2}$ ) using the international classification of BMI [31-33]. For further analysis, overweight/obesity was defined as $\mathrm{BMI} \geq 25 \mathrm{~kg} / \mathrm{m}^{2}$ inclusive of the obese $\left(B M I \geq 30 \mathrm{~kg} / \mathrm{m}^{2}\right)$.

\section{Independent variables: socio-demographic factors}

Age was recorded in complete years and significant past political or social local events were used as a proxy to estimate the ages of some respondents who did not know. Age in years was classified into 6 groups, namely $18-24$, $25-34,35-44,45-54,55-64$ and $\geq 65$ years. Marital status was classified as single, widowed/separated/divorced and cohabiting/married. Religion was classified as Catholic, Protestant, Other Christian, Moslem and Traditionalist. Residence was assessed using the HDSS periurban/rural classification which is based on population size, distance to Iganga town, access to amenities like piped water and mobility of the population. Education level was classified as none, lower primary, upper primary and secondary and above. Occupational activities in the previous month were classified as subsistence agriculture, commercial agriculture, casual labour, domestic work, student, trade and formal salaried employment. Average monthly earnings were assessed in Ugandan shillings (UGX) and classified as none, less than 60,000 (US\$23), $60,000-100,000$ (US\$ $23-38$ ) and more than 100,000 (US\$ 38 (exchange rate September 2014: 1 US\$ = UGX 2,620). Prior to creating the SES index, 27 items were checked for internal consistency using the Cronbach's alpha measure. Fourteen items namely: 1) radio, 2) mobile phone, 3) bicycle, 4) motorcycle, 5) table, 6) machete, 7) axe, 8) hoe, 9) cattle, 10) goats, 11) poultry, 12) land ownership, 13) kerosene lantern, and 14) charcoal iron were identified (Cronbach's alpha $=0.732$ ) and used to create the SES index using principal component analysis. The factor scores of the first principal component were used to create 5 SES quintiles namely: first (poorest), second, third, fourth and fifth (least poor) [34].

\section{Statistical methods}

Double data entry was done using EpiData version 3.1 software, cleaned and exported to IBM SPSS statistics 19 for analysis. Descriptive statistics were computed and expressed by socio-demographic characteristics and BMI. The prevalence estimates for underweight, normal weight, overweight and obesity were computed as percentages with the total sample size as the denominator. Crude odds ratios (COR) and their $95 \% \mathrm{CI}$ were computed to check for associations between categorical variables. All factors significantly associated with overweight/obesity $(p<0.10)$ in the bi-variable analysis such as sex, age, residence, marital status, occupational activities and socio-economic status, were included in the logistic regression model. In addition, an alpha level of 0.10 was used as a criterion for retaining a variable in the final logistic regression model. Logistic regression was used to identify factors associated with being overweight and obese using AOR at $95 \%$ CI.

\section{Ethical considerations}

Ethical approval for the study was obtained from Makerere University School of Public Health Higher Degrees Research and Ethics Committee (IRB00011353) and the Uganda National Council for Science and Technology (HS1322). Permission to conduct the study in the HDSS was also sought from the Iganga-Mayuge HDSS steering committee and written informed consent was obtained from each participant.

We report following the Strengthening the Reporting of Observational Studies in Epidemiology (STROBE) Statement: Guidelines for reporting observational studies [35].

\section{Results}

\section{Characteristics of participants}

Of the 1210 participants, $50.1 \%$ were women, $73 \%$ were married/cohabiting, $55 \%$ were Moslems, $12 \%$ had no formal education and $60 \%$ were involved in subsistence agriculture as the main source of livelihood, Table 1. The mean and median age of women in years were $42.5 \pm 15.3$ and 40.0 (Interquartile range $(\mathrm{IQR})=$ $31.0-52.0)$. The mean and median age of men in years were $43.2 \pm 16.6$ and $42.0(\mathrm{IQR}=30.0-54.0)$.

\section{Prevalence of underweight, normal weight, overweight and obesity}

The mean and median height, weight and BMI for women were $1.58 \pm 0.07 \mathrm{~m}, 1.59 \mathrm{~m}$ (IQR $=1.54-1.63), 61.1 \pm$ $13.1 \mathrm{~kg}, 58.8 \mathrm{~kg}(\mathrm{IQR}=51.6-67.8)$ and $24.4 \pm 5.1 \mathrm{~kg} / \mathrm{m}^{2}$, $22.1 \mathrm{~kg} / \mathrm{m}^{2} \quad(\mathrm{IQR}=20.9-26.4)$. The mean and median height, weight and BMI of men were $1.68 \pm 0.06 \mathrm{~m}$, $1.68 \mathrm{~m}(\mathrm{IQR}=1.64-1.72), 62.0 \pm 9.8 \mathrm{~kg}, 60.3 \mathrm{~kg}$ (IQR = $55.9-67.2)$ and $21.9 \pm 3.1 \mathrm{~kg} / \mathrm{m}^{2}, 21.3 \mathrm{~kg} / \mathrm{m}^{2}(\mathrm{IQR}=19.9-$ 23.0). The mean and median age and BMI were $42.8 \pm$ 16.0 years, $41.0(\mathrm{IQR}=30.0-53.0)$ and $23.2 \pm 4.4 \mathrm{~kg} / \mathrm{m}^{2}$, $22.1 \mathrm{~kg} / \mathrm{m}^{2}(\mathrm{IQR}=20.3-25.0) \mathrm{kg} / \mathrm{m}^{2}$, Table 2 .

Overall, $7 \%$ of the participants were underweight, with no significant difference by sex $(8.1 \%$ of men vs. $5.9 \%$ of women, $p=0.99$ ). The prevalence of underweight was higher in rural areas at $8.1 \%$ versus $4.0 \%$ in the periurban areas, $p=0.26$, Table 3 . Among women of 55-64 years and $\geq 65$ years, the prevalence of underweight was $14.1 \%$ and $15.4 \%$, respectively; and among men, the prevalence of underweight was highest (17.3\%) in the oldest age group, 65 years and above, Additional file 1 .

Eighteen percent of participants were overweight, with significant disparity by sex $(12.4 \%$ of men vs. $23.1 \%$ of women, $p<0.001)$. Obesity was observed in $7 \%$ of the respondents, with significant disparity by sex $(2.0 \%$ of 
Table 1 Socio-demographic characteristics of study participants, $N=1210$

\begin{tabular}{lll}
\hline Characteristics & Number $n$ & Percent (\%) \\
\hline Sex & 604 & 49.9 \\
$\quad$ Male & 606 & 50.1 \\
$\quad$ Female & & \\
Age groups & 167 & 13.8 \\
18-24 & 247 & 20.4 \\
$25-34$ & 297 & 24.5 \\
$35-44$ & 222 & 18.3 \\
$45-54$ & 137 & 11.3 \\
$55-64$ & 140 & 11.6 \\
$\geq 65$ & & \\
Marital status & 130 & 10.3 \\
Single & 193 & 16.0 \\
Widowed/separated/divorced & 887 & 73.3 \\
Cohabiting/Married & &
\end{tabular}

Religion

Catholic
Protestant
Other Christian
Moslem
Traditionalist
Residence

Peri-urban

Rural

Education level

None

Lower primary

Upper primary

Secondary and above

Main occupation in the previous month

Casual labour
Domestic work
Student
Subsistence agriculture
Trade
Commercial agriculture
Formal employment
Average monthly earnings $\left(U G X^{a}\right)$
None
$<60000$
$60000-100000$
$>100000$

Table 1 Socio-demographic characteristics of study participants, $N=1210$ (Continued)

\begin{tabular}{lcc}
\hline SES $^{\text {b }}$ quintiles & \\
First (poorest) & 242 & 20.0 \\
Second & 244 & 20.2 \\
Third & 234 & 19.3 \\
Fourth & 263 & 21.7 \\
Fifth (least poor) & 227 & 18.8 \\
\hline${ }^{a}$ UGX, Ugandan shillings, ${ }^{b}$ SES, socioeconomic status &
\end{tabular}

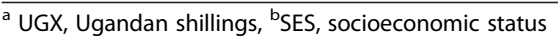

men vs. $12.7 \%$ of women, $p<0.001)$. The prevalence of overweight/obesity was $25.2 \%$. Overweight was more common in the peri-urban areas $(23.8 \%)$ compared to rural areas $(15.8 \%), p<0.001$, Table 3.

The prevalence of overweight was high in middle-aged adults, in age groups $35-44$ years $(29.1 \%$ of women vs. $17.2 \%$ of men) and $45-54$ years (28.8\% of women vs. $17.1 \%$ of men). In the younger age group, 25-34 years, the prevalence of overweight was high among women $(21.8 \%)$ compared to men $(4.2 \%)$. The prevalence of obesity was high $(22.5 \%)$ among women in the age group 45-54 years while the prevalence of obesity among men was highest $(5.4 \%)$ in the age group 55-64 years, Additional file 1.

Both men and women in the two oldest age groups (above 55 years) were shorter in height than those in the age groups below 55 years, Fig. 1. Among women, the age groups below 55 years were on average heavier than the age group $\geq 55$ years while, for men, the middle age groups were heavier than other age groups, Fig. 2.

Table 2 Age, height, weight and body mass index (BMI) by sex

\begin{tabular}{lllll}
\hline & Age (years) & Height $(\mathrm{m})$ & Weight $(\mathrm{kg})$ & $\mathrm{BMl}\left(\mathrm{kg} / \mathrm{m}^{2}\right)$ \\
\hline Women & & & & \\
Mean & 42.5 & 1.58 & 61.1 & 24.4 \\
Median & 40.0 & 1.59 & 58.8 & 22.1 \\
SD $^{\text {a }}$ & 15.3 & 0.07 & 13.1 & 5.1 \\
IQR $^{\mathrm{b}}$ & $31.0-52.0$ & $1.54-1.63$ & $51.6-67.8$ & $20.9-26.4$ \\
Men & & & & \\
Mean & 43.2 & 1.68 & 62.0 & 21.9 \\
Median & 42.0 & 1.68 & 60.3 & 21.3 \\
SD & 16.6 & 0.06 & 9.8 & 3.1 \\
IQR & $30.0-54.0$ & $1.64-1.72$ & $55.9-67.2$ & $19.9-23.0$ \\
F test, $p$-value & $4.93,0.03$ & $2.69,0.10$ & $36.44,0.00$ & $84.16,0.00$ \\
Sexes combined & & & & \\
Mean & 42.8 & 1.63 & 61.6 & 23.2 \\
Median & 41.0 & 1.64 & 59.7 & 22.1 \\
SD & 16.0 & 0.08 & 11.5 & 4.4 \\
IQR & $30.0-53.0$ & $1.57-1.69$ & $54.2-67.4$ & $20.3-25.0$ \\
\hline
\end{tabular}

${ }^{\mathrm{a}} \mathrm{SD}$, standard deviation, ${ }^{\mathrm{b}} \mathrm{IQR}$, interquartile range 
Table 3 Distribution of body mass index by sex, age and residence

\begin{tabular}{|c|c|c|c|c|c|}
\hline Characteristics & Underweight \% & Normal weight \% & Overweight \% & Obesity \% & Chi-square value, $p$-value \\
\hline \multicolumn{6}{|l|}{ Sex } \\
\hline Male & 8.1 & 77.5 & 12.4 & 2.0 & \multirow[t]{3}{*}{$85.3,<0.001$} \\
\hline Female & 5.9 & 58.3 & 23.1 & 12.7 & \\
\hline$p$-value & 0.99 & Reference & $<0.001$ & $<0.001$ & \\
\hline \multicolumn{6}{|l|}{ Age groups } \\
\hline $18-24$ & 3.6 & 83.8 & 9.6 & 3.0 & \multirow[t]{6}{*}{$82.3,<0.001$} \\
\hline $25-34$ & 5.7 & 76.9 & 13.4 & 4.0 & \\
\hline $35-44$ & 5.1 & 62.6 & 23.6 & 8.8 & \\
\hline $45-54$ & 5.0 & 58.6 & 23.0 & 13.5 & \\
\hline $55-64$ & 11.7 & 65.0 & 15.3 & 8.0 & \\
\hline$\geq 65$ & 16.4 & 61.4 & 17.1 & 5.0 & \\
\hline \multicolumn{6}{|l|}{ Residence } \\
\hline Peri-urban & 4.0 & 54.4 & 23.8 & 17.8 & \multirow[t]{4}{*}{$82.0,<0.001$} \\
\hline Rural & 8.1 & 72.3 & 15.8 & 3.9 & \\
\hline$p$-value & 0.26 & Reference & $<0.001$ & $<0.001$ & \\
\hline Overall & 7.0 & 67.9 & 17.8 & 7.4 & \\
\hline
\end{tabular}

Among the middle age groups (35-44 and 45-54), women had a much higher BMI compared to men, Fig. 3.

\section{Factors associated with overweight/obesity}

Factors found to be associated with being overweight/ obese were being female, age $\geq 35$ years, peri-urban residence and higher SES. Females were 4 times more likely to be overweight/obese than males (AOR 4.3; $95 \% \mathrm{CI}$ 3.2-5.9). Participants who were aged 35-44 (AOR 3.1; 95 \% CI 1.8-5.3), 45-54 (AOR 4.1; 95 \% CI 2.3-7.3), 55-64 (AOR 2.6; $95 \%$ CI 1.4-5.0) and $\geq 65$ years (AOR 3.1; 95 \% CI 1.6-6.0) were more likely to be overweight/ obese than those aged 18-24 years. Peri-urban residents were 3 times more likely to be overweight/obese (AOR 2.6; $95 \%$ CI 1.9-3.6) than rural residents. Participants who were in the third (AOR 2.8; $95 \%$ CI 1.7-4.6), fourth (AOR 2.5; $95 \%$ CI 1.5-4.2) and fifth SES quintiles (AOR 2.7: 95 \% CI 1.6-4.4) were more likely to be overweight/ obese than those in the first SES quintile, Table 4.

\section{Discussion}

In this study of randomly selected adults in rural and peri-urban eastern Uganda, we found a relatively low burden of underweight and a high prevalence of overweight and obesity, particularly among middle aged women.

Our findings of a low prevalence of underweight was lower than findings in rural Uganda [14, 15], Kenya [9] and Congo-Brazzaville [36] probably as a result of variations in the age groups studied, definition and measurement of rural-urban divide. However, our findings were similar to those of African studies in Malawi [11], Cameroon [7], Ghana [37] and Nigeria [13, 38]. The higher prevalence of underweight among men $(8.1 \%)$ than women $(5.9 \%)$ is in consonance with findings elsewhere in Africa [7, 9, 10, 14, 15, 37, 39-41]; however, some studies in Africa have reported an insignificant inverse relationship [11, 13, 38].

This peri-urban and rural adult population already has a high burden of overweight $(17.8 \%)$ or obesity $(7.4 \%)$, the two combined affect $25.2 \%$ of the population, comparable to contemporary findings in rural eastern Uganda (17.6 \%) [15] but contrasting with rural southwestern Uganda (11.3\%) [14], probably due to differences in the age composition of study populations. Our findings are consistent with findings in Africa of an overall overweight/obesity prevalence of $21.9 \%$ in Malawi [11], 29.2 \% in Nigeria [13], $20.1 \%$ of the normotensive and $22.2 \%$ of the hypertensive adult populations in Nigeria [42], and $27.1 \%$ of rural residents in Ghana [37]. The overall prevalence estimate of overweight/obesity is less than the estimates in a few studies in Africa, such as $37.1 \%$ in Ghana [37], and $31.6 \%$ in Nigeria [38], probably as a result of differences in the definition and measurement of the rural-urban divide.

Being female was the most significant factor associated with being overweight/obese. This is in consonance with findings in Uganda [15], Mozambique [10], Malawi [11] and Zambia [43]. A higher prevalence of overweight, obesity and overweight/obesity among women than men are consistent with findings in Uganda $[14,15]$. These findings are consistent with findings reported elsewhere in Africa for instance in Nigeria [38, 44], Kenya [9], 

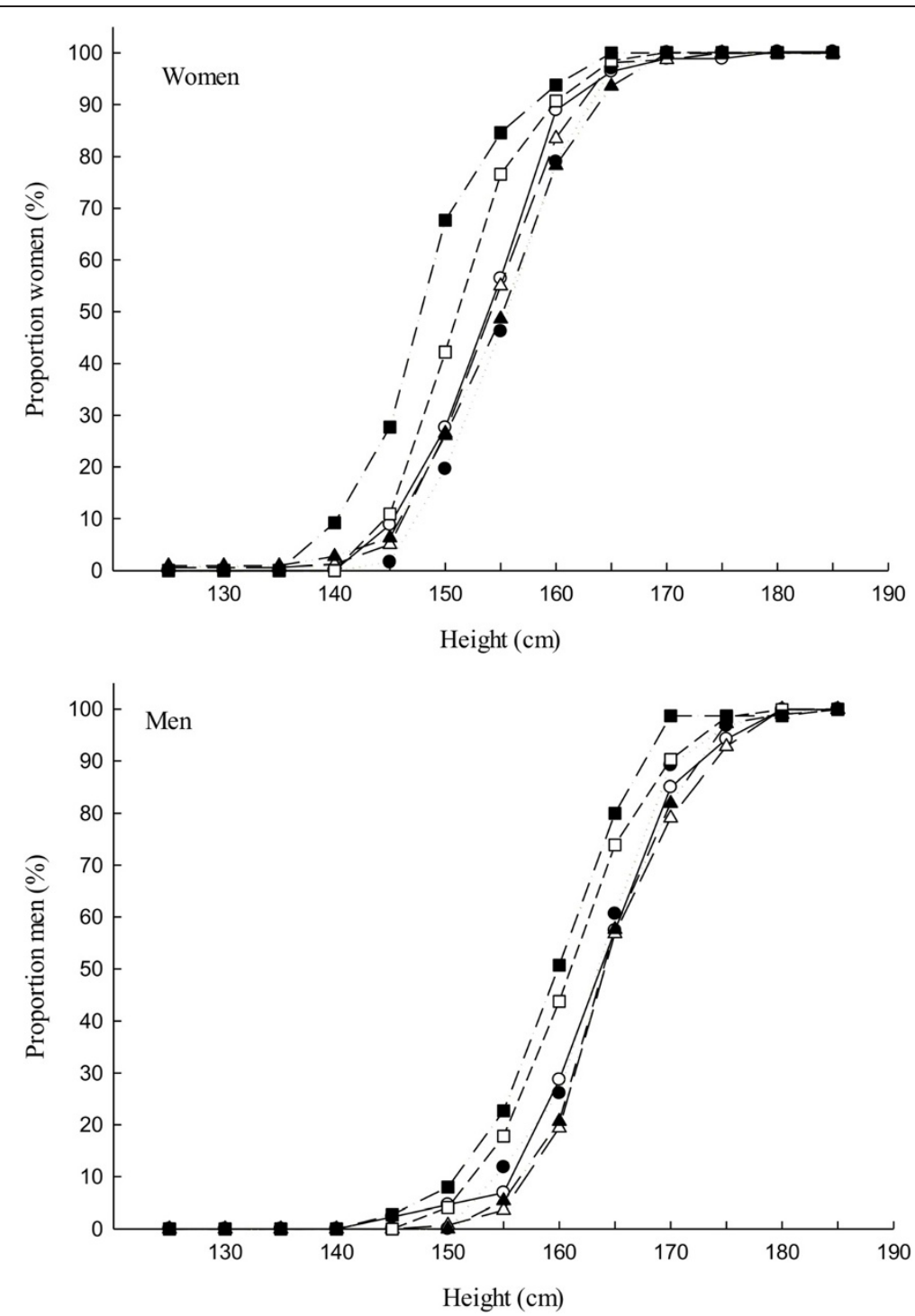

Fig. 1 Distribution of body height ( $\mathrm{cm}$ ) by age group, top) women, bottom) men

Mozambique [10], Malawi [11], Botswana [40], Ghana [37], Zambia [43], Tanzania [45], Algeria [39], South Africa [41, 46] and Cameroon [7]. However, they differ from the findings of one study in Nigeria [13] and studies in high income countries where men have a higher prevalence of overweight/obesity than women [47-49]. These differences can probably be explained by behavioural factors given that both men and women are exposed to the genetic, physical and social environment $[12,50]$. In addition, studies in Africa have reported a social norm of acceptability, or even preference for overweight and obesity particularly among women and it is perceived to be associated with affluence [51-54].

Age was another factor found to be associated with overweight/obesity and has been found in other studies in Africa [10, 11, 15, 40]. It has also been observed that the prevalence of overweight/obesity was highest in the age group 45-54 years and this has been confirmed elsewhere in Africa [10, 11, 15]. Similarly mean BMI was highest in the middle age group, more evidently among the urban than rural residents in Kenya [9] and in Mozambique [10].

Our study affirms that peri-urban residence was another significant factor, similar to findings in Africa $[15,40]$ but contrasting with findings in urban Zambia [43]. It was also observed that the prevalence of overweight/obesity of $41.6 \%$ among peri-urban residents is comparable to $35.7 \%$ reported in peri-urban eastern Uganda [15]. Our study estimates of overweight and obesity of $23.8 \%$ and $17.8 \%$ among peri-urban residents, respectively, are comparable to $18.5 \%$ and $13.1 \%$ of overweight and obesity respectively in Nigeria [38] and also comparable to findings 

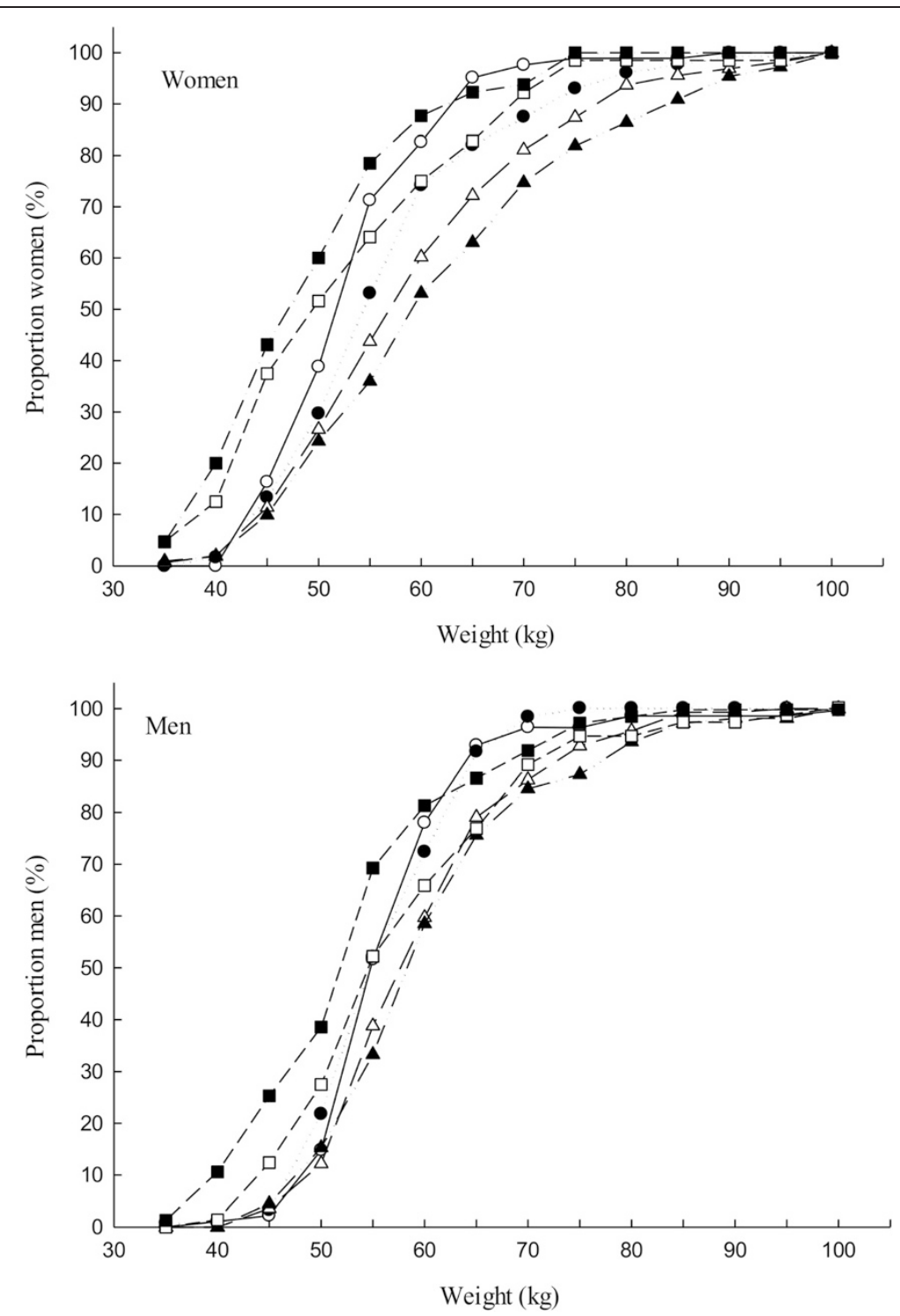

Fig. 2 Distribution of body weight (kg) by age group, top) women, bottom) men

in Zambia [43], Malawi [11], Ghana [37], Mozambique [10], Tanzania and Namibia [55]. Our prevalence estimate is lower than findings in South Africa [56, 57]. The prevalence of obesity among rural residents in our study is comparable to findings in rural Nigeria [44], Malawi [11] and Kenya [9]. A higher prevalence of overweight and obesity among peri-urban residents compared to rural residents could be attributed to rural residents being more actively involved in labour intensive subsistence farming [12] than peri-urban residents whose occupations may encourage sedentariness which is more common in urban areas. However, most studies in Africa have reported a higher prevalence of overweight and obesity in urban areas than to rural areas [9-12, 37, 39, 40, 58-61]. The data is often limited to an urban-rural dichotomy instead of presenting the whole spectrum and therefore, there is paucity on data on overweight and obesity among periurban populations in Africa.

An increase in the prevalence and likelihood of being overweight/obese was observed with increasing SES in our study, indicating that this population could be vulnerable to co-morbidities associated with being overweight or obese. These findings could be explained by the availability of affordable, high energy-dense foods due to urban sprawl, and reduced physical activity resulting into a sedentary lifestyle as observed in a study in Kenya where women who were most sedentary were in the highest income group [62] with the ability to purchase energy-dense foods [63]. These findings have been confirmed in studies in rural Uganda [15], elsewhere in 

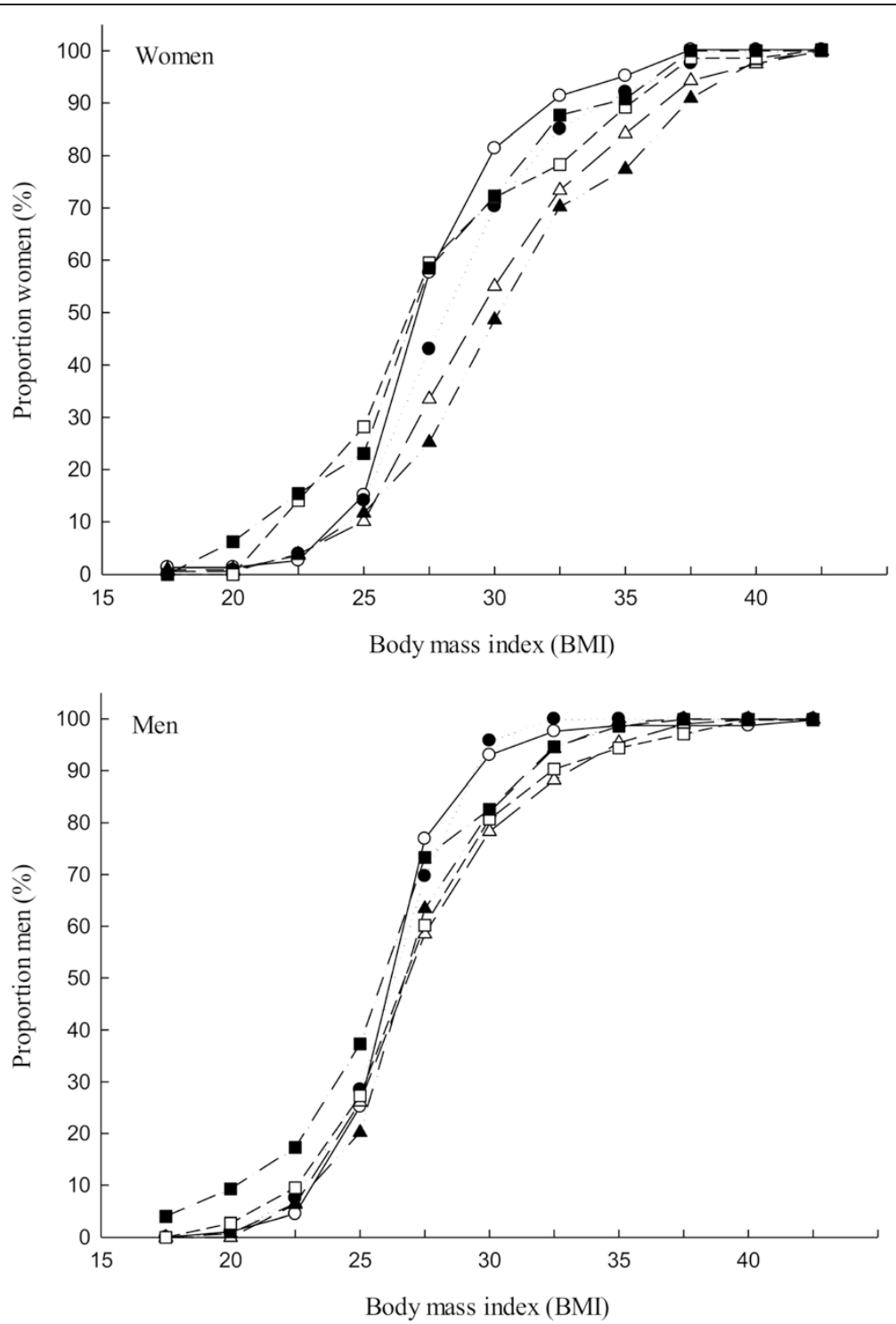

Fig. 3 Distribution of BMl by age groups, top) women, bottom) men

Africa $[45,62]$ and other low- and middle income countries [64], but are in contrast to findings in the high income countries, where the low-income earners are most likely to be overweight/obese. Due to differences in methods of measurement, analysis and categorisation of SES, cross-study comparisons were difficult and limited.

\section{Strengths and limitations}

The main strengths of our study include a large population based, representative study sample which allows comparisons, and a wide age group of 18-92 years, which included younger and older adults, who are often left out of surveys. A small number of trained measurers conducting repeated anthropometric measurements provided fairly accurate and consistent estimates. The SES index was based on relevant specific household items after checking the reliability of each of the items using item analysis. The international classification of BMI recommended by the WHO was used for categorisation.

The study had some methodological limitations. It was cross-sectional in nature and therefore we cannot infer causality. However, the motivation was to describe the distribution of BMI and provide cues to potential associations that can be further explored using robust study designs. Despite the inherent limitations of BMI as a measure of weight status, it remains the most widely used measure for assessing weight status in populations. We acknowledge the relevance of assessing proximate factors for overweight/obesity such as physical activity and dietary intake; however, this was beyond the scope 
Table 4 Factors associated with being overweight or obese (body mass index, BMI $\geq 25 \mathrm{~kg} / \mathrm{m}^{2}$ ), N=1210

\begin{tabular}{|c|c|c|c|c|}
\hline Characteristics & $\mathrm{n}$ & Overweight or obese \% & Crude $\mathrm{OR}^{\mathrm{a}}\left[95 \% \mathrm{Cl}^{\mathrm{b}}\right]$ & Adj $\mathrm{OR}^{\mathrm{a}}\left[95 \% \mathrm{Cl}^{\mathrm{b}}\right]$ \\
\hline \multicolumn{5}{|l|}{ Sex } \\
\hline Male & 604 & 14.4 & 1.0 & 1.0 \\
\hline Female & 606 & 35.8 & $3.3[2.5-4.4]$ & $4.3[3.2-5.9]$ \\
\hline \multicolumn{5}{|l|}{ Age groups } \\
\hline $18-24$ & 167 & 12.6 & 1.0 & 1.0 \\
\hline $25-34$ & 247 & 17.4 & $1.5[0.8-2.6]$ & $1.4[0.8-2.5]$ \\
\hline $35-44$ & 297 & 32.3 & $3.3[2.0-5.6]$ & $3.1[1.8-5.3]$ \\
\hline $45-54$ & 222 & 36.5 & $4.0[2.3-6.8]$ & $4.1[2.3-7.3]$ \\
\hline $55-64$ & 137 & 23.4 & $2.1[1.2-3.9]$ & $2.6[1.4-5.0]$ \\
\hline$\geq 65$ & 140 & 22.1 & $2.0[1.2-3.6]$ & $3.1[1.6-6.0]$ \\
\hline \multicolumn{5}{|l|}{ Residence } \\
\hline Rural & 912 & 19.7 & 1.0 & 1.0 \\
\hline Peri-urban & 298 & 41.6 & $2.9[2.2-3.8]$ & $2.6[1.9-3.6]$ \\
\hline \multicolumn{5}{|l|}{ Marital status } \\
\hline Single & 130 & 10.8 & 1.0 & \\
\hline Widowed/separated/divorced & 125 & 27.5 & $3.1[1.7-5.9]$ & \\
\hline Married/cohabiting & 887 & 26.7 & $3.0[1.7-5.4]$ & \\
\hline \multicolumn{5}{|l|}{ Religion } \\
\hline Christian/traditionalist & 545 & 23.5 & 1.0 & \\
\hline Moslem & 665 & 26.5 & $1.2[0.9-1.5]$ & \\
\hline \multicolumn{5}{|l|}{ Education level } \\
\hline None & 143 & 30.8 & 1.0 & \\
\hline Lower primary & 250 & 24.8 & $0.7[0.5-1.2]$ & \\
\hline Upper primary & 415 & 21.9 & $0.6[0.4-1.0]$ & \\
\hline Secondary and above & 402 & 26.6 & $0.8[0.5-1.2]$ & \\
\hline \multicolumn{5}{|l|}{ Occupation in the previous month } \\
\hline Casual labour & 85 & 16.5 & 1.0 & \\
\hline Domestic work/student & 96 & 32.3 & $2.4[1.2-5.0]$ & \\
\hline Subsistence agriculture & 720 & 20.8 & $1.3[0.7-2.4]$ & \\
\hline Trade & 189 & 40.7 & $3.5[1.8-6.6]$ & \\
\hline Commercial agriculture & 69 & 20.3 & $2.8[1.3-5.7]$ & \\
\hline Formal employment & 51 & 35.3 & $2.8[1.2-6.2]$ & \\
\hline \multicolumn{5}{|l|}{ Average monthly earnings $\left(U G X^{c}\right)$} \\
\hline None & 113 & 22.1 & 1.0 & \\
\hline$<60000$ & 458 & 25.3 & $1.2[0.7-2.0]$ & \\
\hline $60000-100000$ & 344 & 25.3 & $1.2[0.7-2.0]$ & \\
\hline$>100000$ & 295 & 25.8 & $1.2[0.7-2.0]$ & \\
\hline \multicolumn{5}{|l|}{$\mathrm{SES}^{\mathrm{d}}$ quintiles } \\
\hline First (poorest) & 242 & 15.7 & 1.0 & 1.0 \\
\hline Second & 244 & 18.9 & $1.3[0.8-2.0]$ & $1.5[0.9-2.4]$ \\
\hline Third & 234 & 29.9 & $2.3[1.5-3.6]$ & $2.8[1.7-4.6]$ \\
\hline Fourth & 263 & 28.1 & $2.1[1.4-3.3]$ & $2.5[1.5-4.2]$ \\
\hline Fifth (least poor) & 227 & 33.5 & $2.7[1.7-4.2]$ & $2.7[1.6-4.4]$ \\
\hline
\end{tabular}

${ }^{\mathrm{a}}$ OR odds ratio, ${ }^{\mathrm{b}} \mathrm{Cl}$ confidence interval, ${ }^{\mathrm{C}}$ UGX Ugandan shillings, ${ }^{\mathrm{d}} \mathrm{SES}$ socioeconomic status 
of this study. Given that the study was undertaken in the IMHDSS, where there is continuous data collection of demographic characteristics and special studies, during the time of the study, there were no interventional studies on NCDs. Data on human immunodeficiency virus (HIV) was not collected and yet it could have confounded the anthropometric measurements given that wasting and lipodystrophy are characteristic presentations [65]. However, HIV prevalence in the East Central Region where the IMHDSS is located is relatively low at $5.8 \%$ [66], which would not confound the overall picture. Data on the physical and social environment were not collected and yet there are indications that the environment influences lifestyle behaviours such as physical activity and diet, which have an impact on the prevalence of overweight and obesity.

\section{Conclusions}

In the predominantly rural adult population, the prevalence of overweight and overweight/obesity are already high, particularly among women, middle aged adults, peri-urban residents and adults in the higher quintiles of SES. Overweight/obesity appears to occur in significant proportions among young adults, particularly the women. The time has come to try to prevent and control overweight/obesity. Further inquiry is required to understand the perceptions of weight, diet and physical activity in the general population, and describe dietary diversity and physical activity, as well as the influence of the rural physical and social environment on diet, physical activity and BMI so as to guide the design and implementation of appropriate strategies for the prevention and control of overweight and obesity in similar populations.

\section{Additional file}

Additional file 1: Distribution of body mass index by age, sex and sexes combined. Description of data: The table provides details on the distribution of different groups of body mass index stratified by sex and age groups. (XLSX $11 \mathrm{~kb})$

\section{Competing interests}

The authors declare that they have no competing interests.

\section{Authors' contributions}

BEK, LTF, HW, JVB and TT formulated the research questions and designed the study. BEK, JVB and TT elaborated the data gathering methods and database architecture. BEK implemented the study. BEK, LTF, HW, JVB and TT performed the data management and statistical analysis. All authors were active in the interpretation of the results. The article was prepared by BEK, LTF, HW, JVB and TT. All authors have approved the final article.

\section{Acknowledgements}

We thank all the men and women who participated in this study. We also thank the field data collection team for their dedicated and tireless effort to ensure that data collection was successfully completed. This work was supported by the University of Bergen and the Quota Scheme administered by the Norwegian State Educational Loan Fund. These institutions had no role in the design, analysis or writing of this article.

\section{Author details}

${ }^{1}$ Department of Epidemiology and Biostatistics, Makerere University College of Health Sciences, School of Public Health, P.O. Box 7072, Kampala, Uganda. ${ }^{2}$ Centre for International Health, University of Bergen, P.O. Box 7800, 5020 Bergen, Norway. ${ }^{3}$ Department of Clinical Dentistry, University of Bergen, P.O. Box 7800, 5020 Bergen, Norway. ${ }^{4}$ Department of Community Health and Behavioural Sciences, Makerere University College of Health Sciences, School of Public Health, P.O. Box 7072, Kampala, Uganda.

Received: 28 April 2015 Accepted: 17 November 2015

Published online: 24 November 2015

\section{References}

1. Abubakari AR, Lauder W, Agyemang C, Jones M, Kirk A, Bhopal RS Prevalence and time trends in obesity among adult West African populations: a meta-analysis. Obes Rev. 2008;9(4):297-311.

2. Berghofer A, Pischon T, Reinhold T, Apovian CM, Sharma AM, Willich SN. Obesity prevalence from a European perspective: a systematic review. BMC Public Health. 2008;8:200.

3. Muller O, Jahn A. Malnutrition and Maternal and Child Health. Maternal and Child Health: Global Challenges, Programs and Policies. 2009:287-310.

4. World Health Organisation. Ecosystems and Human Well-being: Health Synthesis: A report of the Millennium Ecosystem Assessment. Geneva, Switzerland. World Health Organisation; 2005. WHO Press. ISBN 924 1563095.

5. Campbell T, Campbell A. Emerging disease burdens and the poor in cities of the developing world. J Urban Health. 2007;84(3 Suppl):i54-64.

6. Prentice AM. The emerging epidemic of obesity in developing countries. Int J Epidemiol. 2006;35(1):93-9.

7. Kamadjeu RM, Edwards R, Atanga JS, Kiawi EC, Unwin N, Mbanya JC. Anthropometry measures and prevalence of obesity in the urban adult population of Cameroon: an update from the Cameroon Burden of Diabetes Baseline Survey. BMC Public Health. 2006;6:228.

8. Sodjinou R, Agueh V, Fayomi B, Delisle H. Obesity and cardio-metabolic risk factors in urban adults of Benin: relationship with socio-economic status, urbanisation, and lifestyle patterns. BMC Public Health. 2008:8:84.

9. Christensen DL, Eis J, Hansen AW, Larsson MW, Mwaniki DL, Kilonzo B, et al. Obesity and regional fat distribution in Kenyan populations: impact of ethnicity and urbanization. Ann Hum Biol. 2008;35(2):232-49.

10. Gomes A, Damasceno A, Azevedo A, Prista A, Silva-Matos C, Saranga S, et al. Body mass index and waist circumference in Mozambique: urban/rural gap during epidemiological transition. Obes Rev. 2010;11(9):627-34.

11. Msyamboza KP, Kathyola D, Dzowela T. Anthropometric measurements and prevalence of underweight, overweight and obesity in adult Malawians: nationwide population based NCD STEPS survey. Pan Afr Med J. 2013;15:108.

12. Sola AO, Steven AO, Kayode JA, Olayinka AO. Underweight, overweight and obesity in adults Nigerians living in rural and urban communities of Benue State. Ann Afr Med. 2011;10(2):139-43.

13. Adebayo RA, Balogun MO, Adedoyin RA, Obashoro-John OA, Bisiriyu LA, Abiodun $\mathrm{OO}$. Prevalence and pattern of overweight and obesity in three rural communities in southwest Nigeria. Diabetes Metab Syndr Obes. 2014;7:153-8.

14. Maher D, Waswa L, Baisley K, Karabarinde A, Unwin N, Grosskurth H. Distribution of hyperglycaemia and related cardiovascular disease risk factors in low-income countries: a cross-sectional population-based survey in rural Uganda. Int J Epidemiol. 2011;40(1):160-71.

15. Mayega RW, Makumbi F, Rutebemberwa E, Peterson S, Ostenson CG, Tomson G, et al. Modifiable socio-behavioural factors associated with overweight and hypertension among persons aged 35 to 60 years in eastern Uganda. PLoS One. 2012;7(10):e47632.

16. Agyemang C, Owusu-Dabo E, de Jonge A, Martins D, Ogedegbe G, Stronks K. Overweight and obesity among Ghanaian residents in The Netherlands: how do they weigh against their urban and rural counterparts in Ghana? Public Health Nutr. 2009;12(7):909-16.

17. Assah FK, Ekelund U, Brage S, Corder K, Wright A, Mbanya JC, et al. Predicting physical activity energy expenditure using accelerometry in adults from sub-Sahara Africa. Obesity. 2009;17(8):1588-95. 
18. WHO. Global status report on noncommunicable diseases 2010. Italy 2011. Report No.: ISBN 9789241564229

19. Kozak AT, Daviglus ML, Chan C, Kiefe Cl, Jacobs Jr DR, Liu K. Relationship of body mass index in young adulthood and health-related quality of life two decades later: the Coronary Artery Risk Development in Young Adults study. Int J Obes (Lond). 2011;35(1):134-41. doi:10.1038/ijo.2010.120. Manuscript available in PMC 2013 December 30.

20. Sairenchi T, Iso H, Irie F, Fukasawa N, Ota H, Muto T. Underweight as a predictor of diabetes in older adults: a large cohort study. Diabetes Care. 2008;31(3):583-4.

21. Uganda Bureau of Statistics, and ICF International Inc. Uganda Demographic and Health Survey 2011. Kampala, Uganda 2012.

22. Uganda Bureau of Statistics, and Macro International Inc. Uganda Demographic and Health Survey 2006. Calverton, Maryland: UBOS and Macro International Inc; 2007.

23. Ball K, Timperio AF, Crawford DA. Understanding environmental influences on nutrition and physical activity behaviors: where should we look and what should we count? Int J Behav Nutr Phys Act. 2006;3:33.

24. Casey AA, Elliott M, Glanz K, Haire-Joshu D, Lovegreen SL, Saelens BE, et al. Impact of the food environment and physical activity environment on behaviors and weight status in rural U.S. communities. Prev Med. 2008;47(6):600-4.

25. Oyeyemi AL, Adegoke BO, Oyeyemi AY, Deforche B, De Bourdeaudhuij I, Sallis JF. Environmental factors associated with overweight among adults in Nigeria. Int J Behav Nutr Phys Act. 2012;9:32.

26. Abubakari AR, Bhopal RS. Systematic review on the prevalence of diabetes, overweight/obesity and physical inactivity in Ghanaians and Nigerians. Public Health. 2008;122(2):173-82

27. Scott A, Ejikeme CS, Clottey EN, Thomas JG. Obesity in sub-Saharan Africa: development of an ecological theoretical framework. Health Promot Int. 2013;28(1):4-16

28. Bennett S, Woods T, Liyanage WM, Smith DL. A simplified general method for cluster-sample surveys of health in developing countries. World Health Stat Q. 1991;44(3):98-106.

29. www.igangamayuge-hdss.mak.ac.ug/index.php/en/homepage. [Date accessed 15 July 2013].

30. Ulijaszek SJ, Kerr DA. Anthropometric measurement error and the assessment of nutritional status. Br J Nutr. 1999:82(3):165-77.

31. WHO. Physical status: the use and interpretation of anthropometry. Report of a WHO Expert Committee. Geneva: World Health Organisation; 1995.

32. WHO. Obesity: Preventing and Managing the Global Epidemic. Report of a WHO Consultation. Geneva: World Health Organisation; 2000. Contract No.: 894.

33. WHO. Appropriate body mass index for Asian populations and its implications for policy and intervention strategies. Lancet. 2004;363(9403):157-63.

34. Vyas S, Kumaranayake L. Constructing socio-economic status indices: how to use principal components analysis. Health Policy Plan. 2006;21(6):459-68

35. von Elm E, Altman DG, Egger M, Pocock SJ, Gotzsche PC, Vandenbroucke JP, et al. The Strengthening the Reporting of Observational Studies in Epidemiology (STROBE) statement: guidelines for reporting observational studies. Prev Med. 2007;45(4):247-51.

36. Gartner A, Maire B, Traissac P, Massamba JP, Kameli Y, Keraudren V, et al. Sensitivity and specificity of the body mass index to assess low percent body fat in African women. Am J Hum Biol. 2000;12(1):25-31.

37. Amoah AG. Sociodemographic variations in obesity among Ghanaian adults. Public Health Nutr. 2003;6(8):751-7.

38. Bakari AG, Onyemelukwe C, Sani BG, Aliyu S, Hassan SS, Aliyu TM. Relationship between casual blood sugar and body mass index in a suburban northern Nigerian population: a short communication. Niger J Med. 2007;16(1):77-8.

39. Atek M, Traissac P, El Ati J, Laid Y, Aounallah-Skhiri H, Eymard-Duvernay S, et al. Obesity and association with area of residence, gender and socio-economic factors in Algerian and Tunisian adults. PLoS One. 2013;8(10):e75640.

40. Letamo $\mathrm{G}$. The prevalence of, and factors associated with, overweight and obesity in Botswana. J Biosoc Sci. 2011;43(1):75-84.

41. Malaza A, Mossong J, Barnighausen T, Newell ML. Hypertension and obesity in adults living in a high HIV prevalence rural area in South Africa. PLoS One. 2012;7(10):e47761.

42. Adedoyin RA, Mbada CE, Bisiriyu LA, Adebayo RA, Balogun MO, Akintomide AO. Relationship of anthropometric indicators with blood pressure levels and the risk of hypertension in Nigerian adults. Int J Gen Med. 2008;1:33-40.
43. Rudatsikira E, Muula AS, Mulenga D, Siziya S. Prevalence and correlates of obesity among Lusaka residents, Zambia: a population-based survey. Int Arch Med. 2012;5(1):14

44. Adeyemo A, Luke A, Cooper R, Wu X, Tayo B, Zhu X, et al. A genome-wide scan for body mass index among Nigerian families. Obes Res. 2003;11(2):266-73.

45. Shayo GA, Mugusi FM. Prevalence of obesity and associated risk factors among adults in Kinondoni municipal district, Dar es Salaam Tanzania. BMC Public Health. 2011;11:365

46. Kruger A, Wissing MP, Towers GW, Doak CM. Sex differences independent of other psycho-sociodemographic factors as a predictor of body mass index in black South African adults. J Health Popul Nutr. 2012;30(1):56-65.

47. Elmadfa I, Freisling H. Nutritional status in Europe: methods and results. Nutr Rev. 2009;67 Suppl 1:S130-4

48. Ogden CL, Carroll MD, Curtin LR, McDowell MA, Tabak CJ, Flegal KM. Prevalence of overweight and obesity in the United States, 1999-2004. JAMA. 2006;295(13):1549-55.

49. Hopman WM, Leroux C, Berger C, Joseph L, Barr SI, Prior JC, et al. Changes in body mass index in Canadians over a five-year period: results of a prospective, population-based study. BMC Public Health. 2007;7:150.

50. van der Sande MA, Ceesay SM, Milligan PJ, Nyan OA, Banya WA, Prentice A, et al. Obesity and undernutrition and cardiovascular risk factors in rural and urban Gambian communities. Am J Public Health. 2001;91(10):1641-4.

51. Mayega RW, Etajak S, Rutebemberwa E, Tomson G, Kiguli J. 'Change means sacrificing a good life': perceptions about severity of type 2 diabetes and preventive lifestyles among people afflicted or at high risk of type 2 diabetes in Iganga Uganda. BMC Public Health. 2014;14:864.

52. Holdsworth M, Gartner A, Landais E, Maire B, Delpeuch F. Perceptions of healthy and desirable body size in urban Senegalese women. Int J Obes Relat Metab Disord. 2004;28(12):1561-8.

53. Rguibi M, Belahsen R. Body size preferences and sociocultural influences on attitudes towards obesity among Moroccan Sahraoui women. Body Image 2006:3(4):395-400.

54. Stern R, Puoane T, Tsolekile L. An exploration into the determinants of noncommunicable diseases among rural-to-urban migrants in periurban South Africa. Prev Chronic Dis. 2010;7(6):A131.

55. Hendriks ME, Wit FW, Roos MT, Brewster LM, Akande TM, de Beer $\mid H$, et al. Hypertension in sub-Saharan Africa: cross-sectional surveys in four rural and urban communities. PLoS One. 2012;7(3):e32638.

56. Bourne LT, Lambert EV, Steyn K. Where does the black population of South Africa stand on the nutrition transition? Public Health Nutr. 2002:5(1A):157-62.

57. Puoane T, Steyn K, Bradshaw D, Laubscher R, Fourie J, Lambert V, et al. Obesity in South Africa: the South African demographic and health survey. Obes Res. 2002;10(10):1038-48.

58. Msamati BC, Igbigbi PS. Anthropometric profile of urban adult black Malawians. East Afr Med J. 2000;77(7):364-8.

59. Njelekela M, Kuga S, Nara Y, Ntogwisangu J, Masesa Z, Mashalla Y, et al. Prevalence of obesity and dyslipidemia in middle-aged men and women in Tanzania, Africa: relationship with resting energy expenditure and dietary factors. J Nutr Sci Vitaminol. 2002;48(5):352-8.

60. Siervo M, Grey P, Nyan OA, Prentice AM. Urbanization and obesity in The Gambia: a country in the early stages of the demographic transition. Eur J Clin Nutr. 2006;60(4):455-63.

61. Sobngwi E, Mbanya JC, Unwin NC, Porcher R, Kengne AP, Fezeu L, et al. Exposure over the life course to an urban environment and its relation with obesity, diabetes, and hypertension in rural and urban Cameroon. Int J Epidemiol. 2004;33(4):769-76.

62. Mbochi RW, Kuria E, Kimiywe J, Ochola S, Steyn NP. Predictors of overweight and obesity in adult women in Nairobi Province, Kenya. BMC Public Health. 2012;12:823.

63. Mazengo MC, Simell O, Lukmanji Z, Shirima R, Karvetti RL. Food consumption in rural and urban Tanzania. Acta Trop. 1997;68(3):313-26.

64. Neuman M, Finlay JE, Davey Smith G, Subramanian SV. The poor stay thinner: stable socioeconomic gradients in BMI among women in lowerand middle-income countries. Am J Clin Nutr. 2011;94(5):1348-57.

65. Karmon SL, Moore RD, Dobs AS, Keruly J, Barnett S, Cofrancesco Jr J. Body shape and composition in HIV-infected women: an urban cohort. HIV Med 2005:6(4):245-52

66. Uganda Ministry of Health, ICF International, Centers for Disease Control and Prevention, U.S. Agency for International Development, WHO Uganda. Uganda AIDS Indicator Survey 20112012 August 2012. 